\title{
The effects of antenatal depression and antidepressant treatment on placental gene expression
}

\author{
Jocelien D. A. Olivier ${ }^{1,2,3 *}$, Helena Åkerud ${ }^{1}$, Alkistis Skalkidou ${ }^{1}$, Helena Kaihola $^{1}$ and \\ Inger Sundström-Poromaa ${ }^{1}$
}

${ }^{1}$ Department of Women's and Children's Health, Uppsala University, Uppsala, Sweden

${ }^{2}$ Department of Behavioral Physiology, University of Groningen, Groningen, Netherlands

${ }^{3}$ Department of Medicine, Centre for Gender Medicine, Karolinska Institute, Stockholm, Sweden

Edited by:

Shawn Hayley, Carleton University,

Canada

\section{Reviewed by:}

Xin Wang, Stanford University and HHMI, USA

Zhihong Chen, Cleveland Clinic, USA

\section{*Correspondence:}

Jocelien D. A. Olivier, Department of Behavioral Physiology, Center for Behaviour and Neurosciences,

University of Groningen, Nijenborgh 7, 9747 AG, Groningen, Netherlands e-mail: j.d.a.olivier@rug.nl
The effects of antenatal depression and antidepressant treatment during pregnancy on both mother and child are vigorously studied, but the underlying biology for these effects is largely unknown. The placenta plays a crucial role in the growth and development of the fetus. We performed a gene expression study on the fetal side of the placenta to investigate gene expression patterns in mothers with antenatal depression and in mothers using antidepressant treatment during pregnancy. Placental samples from mothers with normal pregnancies, from mothers with antenatal depression, and from mothers using antidepressants were collected. We performed a pilot microarray study to investigate alterations in the gene expression and selected several genes from the microarray for biological validation with GPCR in a larger sample. In mothers with antenatal depression 108 genes were differentially expressed, whereas 109 genes were differentially expressed in those using antidepressants. Validation of the microarray revealed more robust gene expression differences in the seven genes picked for confirmation in antidepressant-treated women than in depressed women. Among the genes that were validated ROCK2 and C12orf39 were differentially expressed in both depressed and antidepressant-treated women, whereas ROCK1, GCC2, KTN1, and DNM1L were only differentially expressed in the antidepressant-treated women. In conclusion, antenatal depression and antidepressant exposure during pregnancy are associated with altered gene expression in the placenta. Findings on those genes picked for validation were more robust among antidepressant-treated women than in depressed women, possibly due to the fact that depression is a multifactorial condition with varying degrees of endocrine disruption. It remains to be established whether the alterations found in the gene expression of the placenta are found in the fetus as well.

Keywords: antenatal depression, antidepressants, fetal, placenta, gene expression, microarray

\section{INTRODUCTION}

Unfortunately pregnancy is not a lighthearted period for all women. About $10 \%$ of pregnant women in economically developed countries and up to $25 \%$ of pregnant women in poorer countries develop symptoms of depression, such as fatigue, trouble sleeping, sense of sadness or hopelessness, during pregnancy (O'Keane and Marsh, 2007). The 5th edition of the Diagnostic and Statistical Manual of Mental Disorders (DSM-V) also acknowledged the peripartum onset of depression (American Psychiatric Association, 2013). Antenatal depression is not only affecting the mother's well-being but also affects the unborn child and has been associated with child internalizing difficulties (Barker et al., 2011), attention problems (Van Batenburg-Eddes et al., 2012), and violent behavior during adolescence (Hay et al., 2010). Moreover, the risk of developing depression during adolescence (Pawlby et al., 2009) or adulthood (Pearson et al., 2013) is higher. Although the genetic setup of the mother, the hormonal/reproductive history, current stressors, and life experiences are known risk factors (Miller and LaRusso, 2011), the underlying biological mechanisms of antenatal depression and especially its influence on the developing child remain largely unknown. So far one of the mainly suggested biological mechanism underlying the effects of antenatal depression is the activation of the HPA-axis (reviewed in: Field, 2011; Olivier et al., 2014; Waters et al., 2014). In addition to increased cortisol levels Field et al. (2004) also reported on reduced serotonin and dopamine levels in urine samples of depressed pregnant women. Alterations in cortisol/HPA axis responses or in catecholamines/serotonin may explain some effects in the offspring, however the intrauterine environment is directly passed into the embryo-fetal epigenetic programming. For this reason exposure to antenatal depression in utero may also increase the risk for adverse outcome in the offspring via epigenetic alterations (Babenko et al., 2015). Several treatments for antenatal depression are available, including antidepressant treatment. Antidepressants pass the placenta and are found in the amniotic 
fluid (Hostetter et al., 2000; Loughhead et al., 2006). Although the exact effect on the offspring is unknown, the use of antidepressants during pregnancy has increased during the last decades. From 1998 to 2005 a 300\% increase in antidepressant use during pregnancy was reported (Alwan et al., 2011) and this number is still increasing. Selective serotonin reuptake inhibitors (SSRIs) are the most frequently used antidepressants during pregnancy (Andrade et al., 2008), and are generally considered safe (Gentile, 2005). However, epidemiologic studies have found associations between SSRI use and neurodevelopmental disorders, e.g., autism (Croen et al., 2011; Rai et al., 2013), and attention-deficit hyperactivity disorder (Clements et al., 2014). Cohort studies are underway for the study of SSRI use during pregnancy and the neurodevelopmental disorders in the offspring (Malm et al., 2012). Although some SSRI effects during pregnancy have been reported in the offspring (see: Olivier et al., 2013; Bourke et al., 2014) there is still a great need to investigate the molecular mechanisms involved in antenatal depression that may be altered by antidepressants. By unraveling these pathways we generate more insight into the effects of antenatal depression and antidepressant treatment on the developing child, which ultimately helps in future decisions of using antidepressants during pregnancy.

The placenta plays a pivotal role in supporting fetal growth and development and is a crucial regulator of maternal-fetal interactions and fetal brain development (Hsiao and Patterson, 2012). In fact, placental serotonin synthesis directly modulate fetal brain development (Bonnin et al., 2011). As the placenta carries important information about the pregnancy, investigation of the placenta provides valuable insight to the molecular mechanisms that may have both immediate and long lasting effects on fetal health. This study was designed as a hypothesis-generating study and investigated the impact of antenatal depression and antidepressant treatment during pregnancy on the gene expression in the fetal placenta. Placental samples from mothers with normal pregnancies, from mothers with antenatal depression, and from mothers using antidepressants were collected from the "Biology, Affect, Stress, Imaging and Cognition in Pregnancy and the Puerperium" (BASIC) project. In a first pilot microarray experiment 108 genes were differentially expressed in antenatal depressed mothers whereas 109 genes were differentially expressed in those using antidepressants. Of these genes, seven were chosen for biological validation in a larger sample.

\section{MATERIALS AND METHODS SUBJECTS}

This study was carried out at the Department of Women's and Children's health, Uppsala University Hospital, as part of an ongoing longitudinal study on antenatal and postpartum depression: the Biology, Affect, Stress, Imaging and Cognition in Pregnancy and the Puerperium (BASIC) project. The BASIC project started in 2010 and aims to include a study population of 5000 pregnant women in the Uppsala County. Women attending the routine ultrasound examination (gestational week 16-17) at Uppsala University Hospital are approached for participation, enabling a population-based sampling. Upon informed consent, women fill out web-based questionnaires in gestational week 17 and 32 including questions on physical and socio-demographic characteristics, medical, psychiatric, gynecologic and obstetric history variables, lifestyle, medication parameters, and the Swedish version of the Edinburgh Postnatal Depression Scale (EPDS). Information concerning the maternal depression, SSRI use, delivery and neonatal outcome were retrieved from the medical records. Placental biopsies are collected at delivery.

For the specific aim of this sub-study, inclusion criteria were women of Caucasian origin, normal pregnancies and deliveries and healthy offspring (no diagnoses and no admittance to neonatal care). Exclusion criteria were smoking or alcohol use during pregnancy, any daily use of prescribed drugs during pregnancy, any other chronic condition or disease, gestational age $<35$ weeks, and maternal age $<18$ or $>42$ years. Women on antidepressants used their treatment during the entire pregnancy in clinically relevant doses (low-dose use was excluded). The study was approved by the Regional Ethics Committee, Uppsala, Sweden, and performed in accordance with relevant guidelines and regulations.

\section{Study population for micro-array analysis}

Women with pregnancies complicated by ongoing depression $(n=5)$, SSRI treatment $(n=5)$ and women with normal pregnancies $(n=10)$ were selected from the BASIC biobank. Depressed women had medical records confirming major depression and ongoing treatment for their depression in terms of psychotherapy. In the SSRI group sertraline $(n=3)$, fluoxetine $(n=1)$ and escitalopram $(n=1)$ was used. Women on SSRIs displayed significantly lower depression scores than depressed women, i.e., the two groups were not readily comparable (Table 1). Hence, the exposure of ongoing depression or SSRI treatment, respectively, were compared against two control groups. Controls were matched with respective depressed or SSRI-treated women by age ( \pm 2 years), BMI ( \pm one unit) and gestational length $( \pm 1$ week) on an individual level. The control group consisted of women with no history and no current symptoms/diagnoses of mood or anxiety disorders, and their EPDS scores at gestational week 17 and 32 were 6 or lower.

\section{Study population for validation of the microarray}

The samples described above were extended to 24 women with pregnancies complicated by ongoing depression, 29 antidepressant-treated women and 31 women with normal pregnancies. The depressed group included the five microarray cases and 18 women with EPDS $>12$ in gestational week 17 and 32 , or an EPDS score $>14$ on at least one time point $(n=1)$. The average EPDS score for all depressed women was $>15$ in gestational week 17 and 32. The EPDS questionnaire is validated for use in both pregnant and postpartum women (Gibson et al., 2009), and has been validated for the Swedish setting (Rubertsson et al., 2011). The EPDS contains ten items (rated on a scale from 0 to 3 ), based on the past 7 days. While its sensitivity is relatively low, a cut-off score of $>12$ points during pregnancy has a specificity of $98-99 \%$ for major depression (Bergvink et al., 2011). Thirteen of the depressed women were also evaluated by Mini International Neuropsychiatric Interview, which confirmed that all but one (she had social phobia) had major depressive disorder during pregnancy. In the 
Table 1 | Microarray demographic variables in the depressed group, SSRI group, and healthy controls.

\begin{tabular}{|c|c|c|c|c|}
\hline & Depressed Women $(n=5)$ & Healthy controls $(n=5)$ & SSRI-treated Women $(n=5)$ & Healthy controls $(n=5)$ \\
\hline Parity ( $n$, median, range) & $1(0-2)$ & $0(0-1)$ & $0(0-2)$ & $0(0-2)$ \\
\hline Birth weight (gram) & $3542 \pm 461$ & $3632 \pm 342$ & $3538 \pm 225$ & $3556 \pm 275$ \\
\hline Gender offspring ( $\%$ boy) & 60 & 40 & 20 & 80 \\
\hline EPDS score week 32 & $18.8 \pm 5.3^{b}$ & $3.2 \pm 1.6$ & $6.3 \pm 3.4$ & $4.0 \pm 1.2$ \\
\hline
\end{tabular}

Data presented as mean $\pm S D$ or median (range).

${ }^{a}$ significantly greater than both control groups, $P<0.01$, ANOVA post hoc Bonferroni.

${ }^{b}$ significantly greater than all other groups, $P<0.001$, ANOVA post hoc Bonferroni.

antidepressant-treated group, women used sertraline $(n=11)$, fluoxetine $(n=8)$, citalopram/escitalopram $(n=7)$, venlafaxine $(n=2)$ and clomipramine $(n=1)$. Treatment had been initiated by primary care physicians as well as by psychiatrists.

\section{SAMPLE COLLECTION, PROCESSING, AND STORING}

Placental tissues (containing both maternal and fetal side) were obtained after delivery, rinsed carefully in sterile phosphatebuffered saline to wash off maternal and fetal blood, and frozen on dry ice within $60 \mathrm{~min}$ of delivery and stored at $-70^{\circ} \mathrm{C}$ until further use. Each placenta was individually processed as a single biological replicate in the microarray and validation study.

\section{RNA ISOLATION}

\section{Microarray study}

A biopsy was taken with a $3 \mathrm{~mm}$ cube from the fetal side of the placenta. Total RNA was isolated using miRNeasy mini kit (Qiagen, Hilden, Germany). Tissue was lysed with QIAzol reagent (Qiagen) using a rotor-stator homogenizer (up to 33.000 rpm; Ingenieursbúro CAT M Zipper Gmbh, type x120, Staufen, Germany) and chloroform (Sigma Aldrich, St. Louis, MO, USA) was added for phase-separation. The rest of the procedure was performed as described in manufactures protocol.

\section{Validation study}

A biopsy was taken from the fetal side of the placenta with a $3 \mathrm{~mm}$ cube. Total RNA was isolated using RNeasy mini (Qiagen, Hilden, Germany). Tissue was lysed with QIAzol reagent (Qiagen) using TissueLyser $(20 \mathrm{~Hz}, 2 \times 5 \mathrm{~min}$ ) with stainless steel beads (Qiagen) and chloroform was added for phase-separation. The rest of the procedure was performed as described in manufactures protocol.

For both studies RNA concentration was measured with ND1000 spectrophotometer (NanoDrop Technologies, Wilmington, Delaware, USA) and RNA quality was evaluated using the Agilent 2100 Bioanalyzer system (Agilent Technologies Inc, Palo Alto, California, USA).

\section{MICROARRAY EXPRESSION ANALYSIS}

250 nanograms of total RNA from each sample were used to generate amplified and biotinylated sense-strand cDNA from the entire expressed genome according to the Ambion WT Expression Kit (P/N 4425209 Rev B 05/2009) and Affymetrix GeneChip ${ }^{\circledR}$ WT
Terminal Labeling and Hybridization User Manual (P/N 702808 Rev. 4, Affymetrix Inc., Santa Clara, CA). GeneChip ${ }^{\circledR}$ ST Arrays (GeneChip ${ }^{\circledR}$ XXX Gene 1.0 ST Array) were hybridized for $16 \mathrm{~h}$ in a $45^{\circ} \mathrm{C}$ incubator, rotated at $60 \mathrm{rpm}$. According to the GeneChip ${ }^{\circledR}$ Expression Wash, Stain and Scan Manual (PN 702731 Rev 3, Affymetrix Inc., Santa Clara, CA) the arrays were then washed and stained using the Fluidics Station 450 and finally scanned using the GeneChip ${ }^{\circledR}$ Scanner $30007 \mathrm{G}$.

\section{MICROARRAY DATA ANALYSIS}

The raw data was normalized in the free software Expression Console provided by Affymetrix (http://www.affymetrix.com) using the robust multi-array average (RMA) method first suggested by Li and Wong (2001) and Irizarry et al. (2003). Subsequent analysis of gene expression data was carried out in the freely available statistical computing language R (http://www. r-project.org) using packages available from the Bioconductor project (www.bioconductor.org). In order to search for differentially expressed genes between the depressed and controls, and the SSRI and the control groups an empirical Bayes moderated $t$-test with robust regression was applied (Smyth, 2004), using the "limma" package (Smyth, 2005). To address the problem of multiple testing, $p$-values were adjusted according to Benjamini and Hochberg (1995). The Genesis software, version 1.7.1 (http:// genome.tugraz.at/), was used to produce hierarchical clustering and to visualize differentially expressed genes by heat maps (Sturn et al., 2002). The expression data were further analyzed using ingenuity pathway analysis (IPA) in order to determine significantly deregulated genes and pathways (Ingenuity ${ }^{\circledR}$ Systems, Mountain View, CA, USA; www.ingenuity.com). IPA reveals Top genes, which are genes with the largest normalized enrichment scores, and IPA computes a score for each network according to the fit of that network to the user-defined set of Focus Genes. The score, derived from a $p$-value, indicates the likelihood of the association between the set of focus genes (Bonferroni-corrected significance threshold of $P<0.05$ and a fold change of 0.5 ) and a given pathway. The smaller the $p$-value, the less likely that the association is found due to random chance. In general $P$-values below 0.05 indicate a non-random significant association. The $p$-value is calculated using the right-tailed Fisher Exact Test (for more details see www.ingenuity.com). 


\section{cDNA SYNTHESIS}

cDNA was synthesized using SuperScriptIII reversed transcriptase (Invitrogen, Carlsbad, California, USA) according to manufacturer's protocol. Briefly, $250 \mathrm{ng}$ of total RNA was used to reverse transcribe using the random primer to prepare $20 \mu \mathrm{l}$ of cDNA.

\section{REAL-TIME QUANTITATIVE REVERSE TRANSCRIPTASE POLYMERASE CHAIN REACTION ANALYSIS}

The validity of the microarray results was tested via quantitative real-time PCR (qRT-PCR) employing the StepOne Plus qPCR machine (Applied Biosystems, Life Technologies, Carlsbad, California, USA). For validation we selected seven genes [NEXN (Hs00332124_m1), GCC2 (Hs00206083_m1), ROCK 1 (Hs01127699_m1), ROCK2 (Hs00178154_m1), DNM1 (Hs00247147_m1), KTN1 (Hs00192160_m1), and C12ORF39 (Hs00228976_m1)] which showed a fold change (FC) > 0.5 in the microarray. GAPDH (Hs99999905_m1) and $\beta$-actin (4326315E) were selected as reference genes for normalization. cDNA of the samples was used for quantification. TaqMan Gene expression Assay primers, probes and gene expression master mix (all Applied Biosystems, Life Technologies, Carlsbad, CA, USA) were used to run the qRT-PCR according to manufacturer's instructions. Mean plate efficiencies were calculated by LinReg.

\section{qPCR DATA ANALYSIS}

All samples were performed in triplicates and averaged for further calculations. Mean normalized expression (MNE) based on the ratio between $C t$-values of target and reference genes and the efficiency of the PCR reactions, was calculated as a measure of target gene transcription, as described previously (Muller et al., 2002; Helmestam et al., 2012). Data are presented as $\log _{2} \mathrm{MNE}$ to illustrate the difference between the groups.

\section{STATISTICS}

Clinical characteristics of women in the microarray study and the validation study were compared by means of One-Way ANOVA, followed by a Bonferroni post hoc test when appropriate. Differences in expression between subsets in the validation study (qPCR) were calculated using a univariate ANOVA with age, BMI, parity, and week of delivery as covariates. Data were analyzed using the SPSS 20.0 software. Level of significance was set at $P<0.05$. Data are presented as mean \pm S.E.M.

\section{RESULTS \\ SUBJECTS}

The demographic characteristics of the women in the microarray and validation studies are presented in Tables 1, 2. Microarray study: A significant group difference was found for EPDS scores at gestational week $17\left[F_{(3,18)}=8.9, P<0.01\right]$ and gestational week $32\left[F_{(3,17)}=22.8, P<0.001\right]$. Depressed women had significantly higher EPDS scores in gestational week 17 and 32 compared with controls $(P<0.01)$, whereas women on SSRIs did not differ from controls at any time-point. In gestational week 32, depressed women also had significantly higher EPDS scores than SSRI-treated women, Table 1. Validation study: All women on SSRI treatment reported previous anxiety and/or depression at the first antenatal booking, whereas $41 \%$ of depressed cases had no previous psychiatric history. Women using antidepressants had a significantly shorter gestational length than controls $(P<0.01)$. As expected, significant group differences were found in EPDS scores at gestational weeks $17\left[F_{(2,74)}=69.6\right.$, $P<0.001]$ and $32\left[F_{(2,74)}=74.3, P<0.001\right]$. In gestational week 17 and 32, depressed women had significantly higher EPDS scores than antidepressant-treated women $(P<0.001$ and $P<$ 0.001, respectively), whom in turn had higher EPDS scores than controls $(P<0.001$ and $P<0.001$, respectively), Table 2 . No other parameters differed between groups.

Table 2 | Validation demographic variables in the depressed group, SSRI group, and healthy controls.

\begin{tabular}{lccc}
\hline & Healthy controls $(\boldsymbol{n}=\mathbf{3 1})$ & Depressed women $(\boldsymbol{n}=\mathbf{2 4})$ & SSRI-treated Women $(\boldsymbol{n}=\mathbf{2 9})$ \\
\hline Age (years) & $31.4 \pm 3.9$ & $31.1 \pm 4.3$ & $31.2 \pm 4.1$ \\
Parity $(n$, median, range) & $0(0-3)$ & $1(0-2)$ & $1(0-3)$ \\
BMI (kg/m $\left.{ }^{2}\right)$ & $26.0 \pm 4.9$ & $24.0 \pm 6.2$ & $27.2 \pm 4.9$ \\
Systolic blood pressure in first trimester, $\mathrm{mmHg}$ & $119 \pm 13$ & $111 \pm 12$ & $118 \pm 12$ \\
Diastolic blood pressure in first trimester, $\mathrm{mmHg}$ & $73 \pm 9$ & $69 \pm 7$ & $70 \pm 7$ \\
Systolic blood pressure at last visit, $\mathrm{mmHg}$ & $125 \pm 11$ & $119 \pm 11$ & $76 \pm 6$ \\
Diastolic blood pressure at first visit, $\mathrm{mmHg}$ & $79 \pm 8$ & $11.4 \pm 0.8$ & $77 \pm 7$ \\
Lowest hemoglobin level during pregnancy, g/dl & $11.7 \pm 0.8$ & $3546 \pm 499$ & $11.0 \pm 0.9^{\mathrm{c}}$ \\
Birth weight (gram) & $3577 \pm 351$ & 54 & $3589 \pm 400$ \\
Gender offspring (\% boy) & 65 & $275 \pm 11$ & 45 \\
Gestational length & $281 \pm 7$ & $15.0 \pm 4.2^{\mathrm{a}}$ & $273 \pm 8^{\mathrm{c}}$ \\
EPDS score week 17 & $2.9 \pm 1.8$ & $15.9 \pm 3.6^{\mathrm{a}}$ & $7.7 \pm 4.9^{\mathrm{b}}$ \\
EPDS score week 32 & $2.9 \pm 1.8$ & $8.7 \pm 5.3^{\mathrm{bd}}$ & \\
\hline
\end{tabular}

Data presented as mean $\pm S D$ or median (range).

a significantly higher than all other groups, $P<0.001$, ANOVA post hoc Bonferroni.

${ }^{b}$ significantly higher than healthy control group, $P<0.001$, ANOVA post hoc Bonferroni.

${ }^{c}$ significantly lower than healthy control group, $P<0.01$, ANOVA post hoc Bonferroni.

${ }^{d}$ significantly lower than depressed group, $P<0.001$, ANOVA post hoc Bonferroni. 


\section{DIFFERENTIALLY EXPRESSED GENES AND PATHWAYS BETWEEN THE DEPRESSED AND CONTROL PLACENTAS}

At a Bonferroni-corrected significance threshold $(P<0.05)$ and a log2-fold change of 0.5 or higher we found 108 genes differentially expressed between the depressed women and their respective controls; 100 were down-regulated and 8 up-regulated, see Table 3. The raw microarray data is found as an excel file in the Supplementary Data. The ingenuity pathway analysis (IPA) revealed 17 differentially expressed top genes; 7 were up-regulated and 10 down-regulated. Top up- and down-regulated molecules are summarized in Table 4. We then clustered placentas according to their gene expression profiles for the 17 genes that displayed differential expression (see Figure 1A). In order to determine the biological relevance, analysis with IPA was performed, focusing on genes that differed in expression between placentas from depressed women and controls. As shown in Table 5, we identified five gene networks that were significantly enriched, classified as follows: (I) DNA Replication, Recombination, and Repair, Cellular Assembly and Organization, Cell Cycle with an IPA score of 27; (II) Cell Cycle, Cancer, Connective Tissue Disorders with a IPA score of 18; (III) Cellular movement, Hematological System Development and Function, Immune Cell Trafficking with an IPA score of 16; (IV) Cardiovascular System Development and Function, Organismal Development, Visual System Development and Function with an IPA score of 14; and (V) Molecular Transport, RNA Trafficking, Connective Tissue Disorders with an IPA score of 9 (Table 5). Further, the significant canonical pathways identified by IPA $(P<0.05)$ are shown in Table 6, along with the included genes and $p$-values. Pathways included Actin Nucleation by ARP-WASP Complex, RhoA Signaling, VEGF Signaling, Protein Kinase A Signaling, and 1D-myo-inositol Hexakisphosphate Biosynthesis V [from Ins $(1,3,4) \mathrm{P} 3]$.

\section{DIFFERENTIALLY EXPRESSED GENES AND PATHWAYS BETWEEN SSRI-TREATED AND CONTROL PLACENTAS}

Similarly, we found 109 genes to be differentially expressed between the SSRI-treated women and their respective controls at a Bonferroni-corrected significance $(P<0.05)$ threshold with a fold change of 0.5 or higher. 82 genes were down-regulated and 27 up-regulated, see Table 7. The raw microarray data is found as an excel file in the Supplementary Data. IPA analysis revealed 20 differentially expressed top genes, of which 10 were up- and 10 down-regulated (see Table 8). We then clustered placentas according to their gene expression profiles for the 20 genes that displayed differential expression (see Figure 1B). With use of IPA we focused on genes that differed in expression between placentas from antidepressant-treated women and controls. As shown in Table 9, we identified five gene networks that were significantly enriched. Of biological relevance were: (I) Infectious Disease, Cellular Assembly and Organization, Cellular Function and Maintenance with an IPA score of 13; (II) Cellular Growth and Proliferation, Inflammatory Response, Lipid Metabolism with an IPA score of 11; (III) Cell Death and Survival, Inflammatory Response, Cellular Movement with an IPA score of 9; (IV) Cell death and Survival, Liver Necrosis/Cell Death, Hematological System Development and Function with an IPA score of 8; and (V) Cardiovascular Disease, Skeletal and Muscular Disorders, Cardiovascular System Development and Function with an IPA score of 2. Further, the significant canonical pathways identified by IPA $(P<0.05)$ are shown in Table 10, along with the included genes and $p$-values. Pathways included Ephrin A Signaling, RhoA Signaling, PEDF Signaling, Breast Cancer Regulation by Stathmin1, and Signaling by Rho Family GTPases.

\section{COMMONLY ALTERED GENES IN DEPRESSED AND SSRI-TREATED GROUPS}

Of the 108 genes that were differentially expressed between the depressed and the control cases, and the 109 genes that were differentially expressed between the SSRI-treated and the control cases, only 20 genes were overlapping. These genes are displayed in Table 11.

\section{VALIDATION OF MICROARRAY DATA USING qPCR ANALYSIS}

For validation of the microarray results we selected seven genes that were detected in top up- or down-regulated genes, in the pathway analysis or in the canonical pathway analysis in placental tissue of both depressed and antidepressant-treated women. ROCK1 and ROCK2 are both involved in the actin nucleation by ARP-WASP complex, RhoA signaling, VEGF Signaling and protein kinase A signaling in the canonical pathway analysis of depressed women. Moreover they also appeared in the canonical pathway analysis of ephrin A Signaling, RhoA signaling, PEDF signaling, breast cancer regulation by stathmin 1 and signaling by Rho family GTPases of antidepressant-treated women. In addition, ROCK1 and GCC2 belonged to the top down-regulated genes in depressed as well as antidepressant-treated women and ROCK2 is a top down-regulated gene in the depressed women as well. KTN1 is involved in molecular transport, RNA trafficking, connective tissue disorders pathway of depressed women, but also in infectious disease, cellular assembly and organization, cellular function and maintenance pathway of antidepressant-treated women. Moreover, KTN1 is involved in the RhoA signaling of the canonical pathway analysis in both depressed and antidepressant women. DNM1L is involved in cardiovascular system development and function, organismal development, visual system development and function of the pathway analysis in depressed women but also in cell death and survival, inflammatory response, cellular movement pathway analysis of antidepressant-treated women. NEXN was the top down-regulated gene in antidepressanttreated women and also turned out to be involved in cardiovascular disease, skeletal and muscular disorders, cardiovascular system development and function pathway in antidepressanttreated women. Finally, C12orf39 was chosen as it appeared to be the top up-regulated gene in antidepressant-treated women.

In the placenta of depressed women (Figure 2A) a significant down-regulation compared to placenta of controls was found for the C12orf39 gene $\left[F_{(1,45)}=3.83, p=0.05\right]$ and a tendency for down-regulation of the ROCK2 gene was found $\left[F_{(1,44)}=3.03\right.$, $p=0.08]$. No other genes were differentially expressed between control and depressed placentas $\left(\operatorname{NEXN}\left[F_{(1,45)}=0.57\right]\right.$, GCC2 $\left[F_{(1,45)}=0.52\right]$, ROCK $1\left[F_{(1,45)}=2.43\right]$, DNM1L $\left[F_{(1,45)}=\right.$ 
Table 3 | Significantly up and down regulated genes in the control vs. depressed groups (- = reduction in expression levels).

\begin{tabular}{|c|c|c|c|}
\hline Gene symbol & Gene name & Probe ID & Log2 fold change \\
\hline VTRNA1-2 & vault RNA 1-2 & 8108629 & 2.280673826 \\
\hline PGF & placental growth factor & 7980233 & 0.695475147 \\
\hline RNH1 /// FLJ23519 & ribonuclease/angiogenin inhibitor 1 /// hypothetical protein FLJ23519 & 7945420 & 0.565671098 \\
\hline ITPK 1 & inositol 1,3,4-triphosphate 5/6 kinase & 7980970 & 0.549075065 \\
\hline $\operatorname{mir} 503$ & - & 8175261 & 0.519417648 \\
\hline$R A D 23 A$ & RAD23 homolog A (S. cerevisiae) & 8026122 & 0.51907744 \\
\hline FAM183B & acyloxyacyl hydrolase (neutrophil) & 8139160 & 0.50922813 \\
\hline APOC1 & apolipoprotein C-I & 8029536 & 0.502399918 \\
\hline KIR3DL2 /// KIR2DS2 /// KIR2DL2 /// & killer cell immunoglobulin-like receptor, three domains, long & 8031293 & -0.506084964 \\
\hline
\end{tabular}

\begin{tabular}{|c|c|c|c|}
\hline SNX4 & sorting nexin 4 & 8090256 & -0.506251931 \\
\hline NEK1 & NIMA (never in mitosis gene a)-related kinase 1 & 8103646 & -0.50748106 \\
\hline RALGPS2 & Ral GEF with PH domain and SH3 binding motif 2 & 7907657 & -0.508099708 \\
\hline RNF160 & ring finger protein 160 & 8069711 & -0.50811689 \\
\hline- & - & 8104012 & -0.508994997 \\
\hline RIF1 & RAP1 interacting factor homolog (yeast) & 8045697 & -0.511151224 \\
\hline$L R P 2$ & low density lipoprotein-related protein 2 & 8056611 & -0.513852689 \\
\hline PTBP2 & polypyrimidine tract binding protein 2 & 7903188 & -0.517797539 \\
\hline ZMAT1 & zinc finger, matrin type 1 & 8174119 & -0.519592242 \\
\hline$R U F Y 2$ & RUN and FYVE domain containing 2 & 7933999 & -0.524450233 \\
\hline SNAPC1 & small nuclear RNA activating complex, polypeptide 1,43kDa & 7974870 & -0.52596952 \\
\hline$R N F 19 A$ & ring finger protein $19 \mathrm{~A}$ & 8152041 & -0.526515918 \\
\hline SKIV2L2 & superkiller viralicidic activity 2-like 2 (S. cerevisiae) & 8105353 & -0.530773126 \\
\hline ANAPC4 & anaphase promoting complex subunit 4 & 8094408 & -0.533126207 \\
\hline- & - & 7916667 & -0.533554256 \\
\hline NCKAP1 & NCK-associated protein 1 & 8057517 & -0.53822831 \\
\hline$D G K H$ & diacylglycerol kinase, eta & 7968800 & -0.538998035 \\
\hline MARCH7 & membrane-associated ring finger $(\mathrm{C} 3 \mathrm{HC} 4) 7$ & 8045919 & -0.550742909 \\
\hline HOMER1 & homer homolog 1 (Drosophila) & 8112841 & -0.551657356 \\
\hline PHF2OL1 & PHD finger protein 20-like 1 & 8148358 & -0.551986952 \\
\hline YEATS4 & YEATS domain containing 4 & 7957032 & -0.55366204 \\
\hline CHRM3 & cholinergic receptor, muscarinic 3 & 7910915 & -0.554183212 \\
\hline$P D E 3 B$ & phosphodiesterase 3B, cGMP-inhibited & 7938629 & -0.557038965 \\
\hline$B R M S 1 L$ & breast cancer metastasis-suppressor 1-like & 7973948 & -0.55836529 \\
\hline SNORD30 & small nucleolar RNA, C/D box 30 & 7948900 & -0.560928764 \\
\hline ZNF84 & zinc finger protein 84 & 7960143 & -0.562597276 \\
\hline MND1 & meiotic nuclear divisions 1 homolog (S. cerevisiae) & 8097857 & -0.5650204 \\
\hline LOC221442 & adenylate cyclase 10 pseudogene & 8119423 & -0.565773386 \\
\hline UBA6 & ubiquitin-like modifier activating enzyme 6 & 8100615 & -0.566611488 \\
\hline N4BP2L2 & NEDD4 binding protein 2-like 2 & 7970907 & -0.570303348 \\
\hline ZRANB2 & zinc finger, RAN-binding domain containing 2 & 7916969 & -0.573773594 \\
\hline EIF5B & eukaryotic translation initiation factor $5 \mathrm{~B}$ & 8043861 & -0.574408988 \\
\hline NAP1L1 & nucleosome assembly protein 1-like 1 & 7965048 & -0.581711065 \\
\hline
\end{tabular}


Table 3 | Continued

\begin{tabular}{|c|c|c|c|}
\hline Gene symbol & Gene name & Probe ID & Log2 fold change \\
\hline BRWD3 & bromodomain and WD repeat domain containing 3 & 8173766 & -0.592331241 \\
\hline SENP7 & SUMO1/sentrin specific peptidase 7 & 8089203 & -0.603487152 \\
\hline FZD6 & frizzled homolog 6 (Drosophila) & 8147766 & -0.605426406 \\
\hline CHD9 & chromodomain helicase DNA binding protein 9 & 7995583 & -0.607612535 \\
\hline RNF217 & ring finger protein 217 & 8121825 & -0.620970732 \\
\hline PCMTD1 & $\begin{array}{l}\text { protein-L-isoaspartate (D-aspartate) O-methyltransferase domain } \\
\text { containing } 1\end{array}$ & 8150714 & -0.635640315 \\
\hline NKTR & natural killer-tumor recognition sequence & 8079079 & -0.63772807 \\
\hline KIF23 & kinesin family member 23 & 7984540 & -0.649229354 \\
\hline PRPF40A & PRP40 pre-mRNA processing factor 40 homolog A (S. cerevisiae) & 8055913 & -0.652162751 \\
\hline NIPBL & Nipped-B homolog (Drosophila) & 8104944 & -0.6642255 \\
\hline CENPE & centromere protein $\mathrm{E}, 312 \mathrm{kDa}$ & 8102076 & -0.664227054 \\
\hline$B O D 1 L$ & biorientation of chromosomes in cell division 1-like & 8099410 & -0.665905703 \\
\hline TAF1D & $\begin{array}{l}\text { TATA box binding protein (TBP)-associated factor, RNA polymerase I, } \\
\text { D, } 41 \mathrm{kDa}\end{array}$ & 7951008 & -0.668975157 \\
\hline PIBF1 & progesterone immunomodulatory binding factor 1 & 7969390 & -0.670731182 \\
\hline SENP6 & SUMO1/sentrin specific peptidase 6 & 8120758 & -0.675080818 \\
\hline SMC2 & structural maintenance of chromosomes 2 & 8156982 & -0.681747538 \\
\hline DNAJC10 & DnaJ (Hsp40) homolog, subfamily C, member 10 & 8046759 & -0.690820266 \\
\hline ZNF638 & zinc finger protein 638 & 8042601 & -0.696757481 \\
\hline STXBP3 & syntaxin binding protein 3 & 7903541 & -0.698824428 \\
\hline DNM1L & dynamin 1-like & 7954752 & -0.716232722 \\
\hline CEP152 & centrosomal protein $152 \mathrm{kDa}$ & 7988537 & -0.717688618 \\
\hline OTUD6B & OTU domain containing 6B & 8147262 & -0.735794509 \\
\hline ATRX & $\begin{array}{l}\text { alpha thalassemia/mental retardation syndrome X-linked (RAD54 } \\
\text { homolog, S. cerevisiae) }\end{array}$ & 8173673 & -0.740293061 \\
\hline ZNF100 & zinc finger protein 100 & 8035808 & -0.741413733 \\
\hline KIF18A & kinesin family member $18 \mathrm{~A}$ & 7947248 & -0.743358618 \\
\hline$D E K$ & DEK oncogene & 8124144 & -0.744034441 \\
\hline- & - & 8083445 & -0.766235985 \\
\hline- & - & 8119580 & -0.77576534 \\
\hline SDCCAG1 & serologically defined colon cancer antigen 1 & 7978866 & -0.776418378 \\
\hline ANKRD36B & ankyrin repeat domain 36B & 8054064 & -0.777582301 \\
\hline ANKRD26 & ankyrin repeat domain 26 & 7932637 & -0.779453671 \\
\hline LYSMD3 & LysM, putative peptidoglycan-binding, domain containing 3 & 8113064 & -0.780972234 \\
\hline $\begin{array}{l}\text { CTAGE4 /// CTAGE6 ///L LOC100142659 } \\
\text { /// LOC441294 /// hCG_2030429 }\end{array}$ & $\begin{array}{l}\text { CTAGE family, member } 4 \text { /// CTAGE family, member } 6 \text { /// CTAGE } \\
\text { family member /// similar to CTAGE6 /// CTAGE family, member 4-like }\end{array}$ & 8136979 & -0.78257421 \\
\hline SUCLA2 & succinate-CoA ligase, ADP-forming, beta subunit & 7971541 & -0.78881152 \\
\hline SMC5 & structural maintenance of chromosomes 5 & 8155770 & -0.795143951 \\
\hline
\end{tabular}


Table 3 | Continued

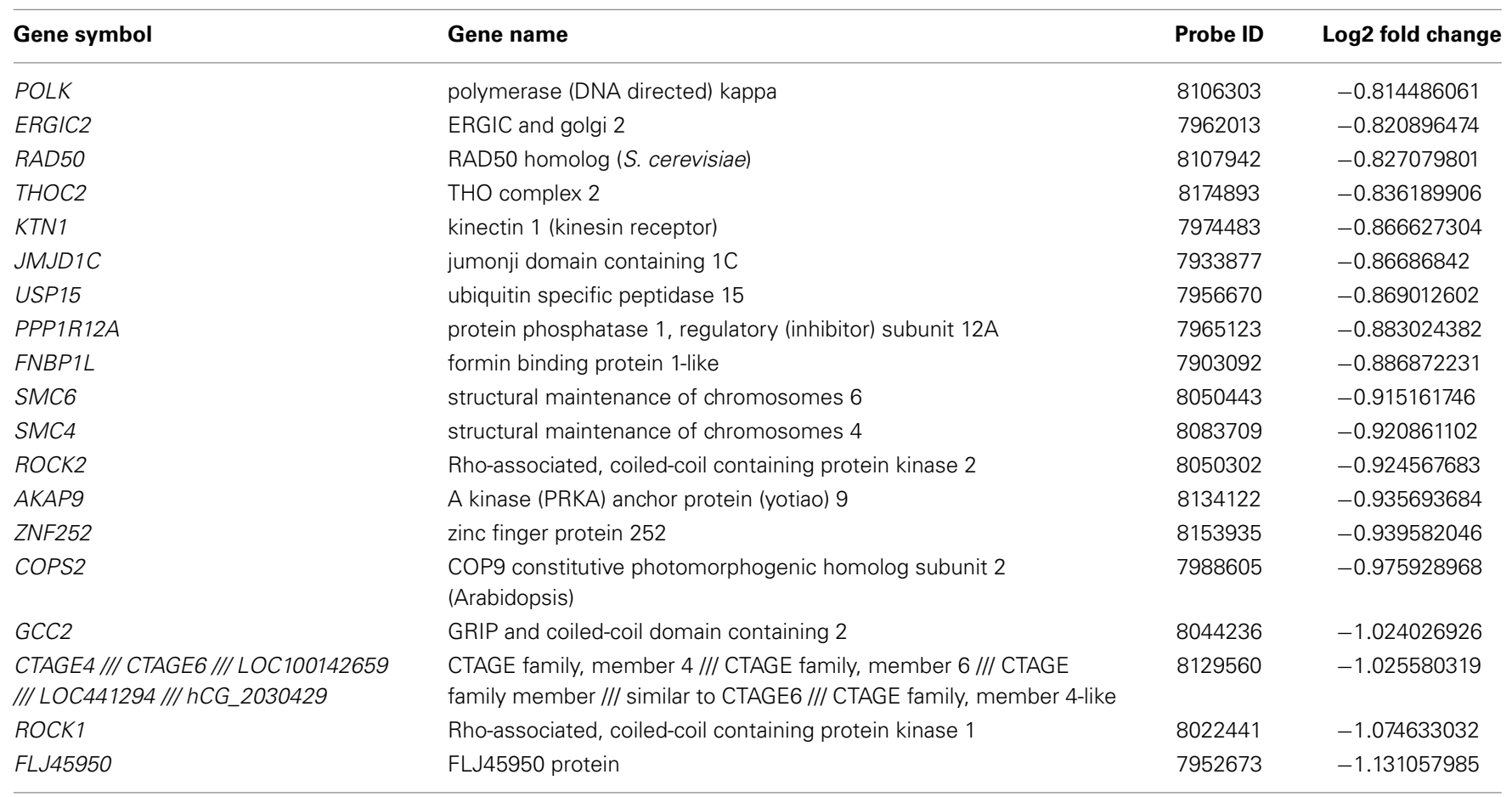

Table 4 | Significantly up- and down-regulated top molecules in the control vs. the depressed group (- = reduction in expression levels).

\begin{tabular}{|c|c|c|c|}
\hline Gene symbol & Gene title & log2 fold change & $P$-value \\
\hline$P G F$ & Placenta growth factor & 0.70 & 0.013 \\
\hline ITPK1 & inositol 1,3,4-triphosphate 5/6 kinase & 0.55 & 0.037 \\
\hline Mir-503 & microRNA 503 & 0.52 & 0.047 \\
\hline$R A D 23 A$ & RAD23 homolog A (S. cerevisiae) & 0.52 & 0.013 \\
\hline USP15 & ubiquitin specific peptidase 15 & -0.87 & 0.026 \\
\hline PPP1R12A & protein phosphatase 1. regulatory (inhibitor) subunit $12 \mathrm{~A}$ & -0.88 & 0.021 \\
\hline FNBP1L & formin binding protein 1-like & -0.89 & 0.046 \\
\hline SMC6 & structural maintenance of chromosomes 6 & -0.92 & 0.026 \\
\hline SMC4 & structural maintenance of chromosomes 4 & -0.92 & 0.024 \\
\hline ROCK1 & Rho-associated. coiled-coil containing protein kinase 1 & -1.07 & 0.028 \\
\hline
\end{tabular}

2.53] and KTN1 $\left.\left[F_{(1,44)}=1.57\right]\right)$. When the placental gene expression was compared between antidepressant-treated women and controls (Figure 2B), we found a significant down-regulation of ROCK1 $\left[F_{(1,47)}=4.26, P<0.05\right], \operatorname{ROCK} 2\left[F_{(1,46)}=9.48\right.$, $P<0.01]$, GCC2 $\left[F_{(1,47)}=3.78, p=0.05\right]$, KTN1 $\left[F_{(1,46)}=\right.$ 6.31, $P<0.05]$, DNM1L $\left[F_{(1,47)}=6.40, P<0.05\right]$, and a tendency for down-regulation of C12orf39 $\left[F_{(1,47)}=3.39, P=\right.$ 0.07]. The gene expression of $\operatorname{NEXN}\left[F_{(1,47)}=1.28, \mathrm{~ns}\right]$ did not differ between antidepressant-treated women and controls.

\section{DISCUSSION}

We performed a gene expression study in the fetal placenta of depressed women and antidepressant-treated women, and compared them with the gene expression of the placentas from women with normal pregnancies. We found that antenatal depression and antidepressant exposure during pregnancy has an influence on the gene expression of the placenta. In the microarray 108 genes were differentially expressed in women with antenatal depression, while 109 genes were differentially 
A
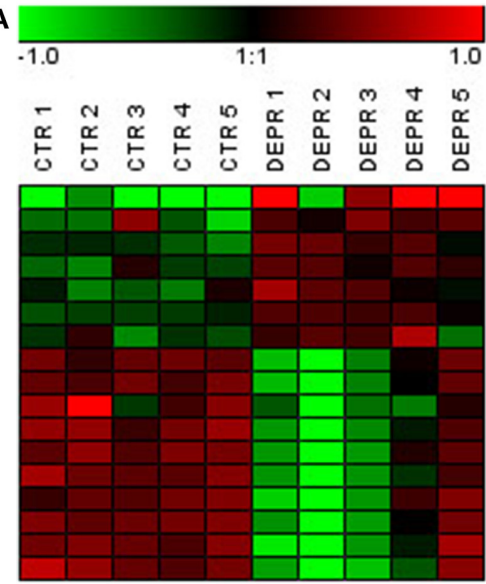

B

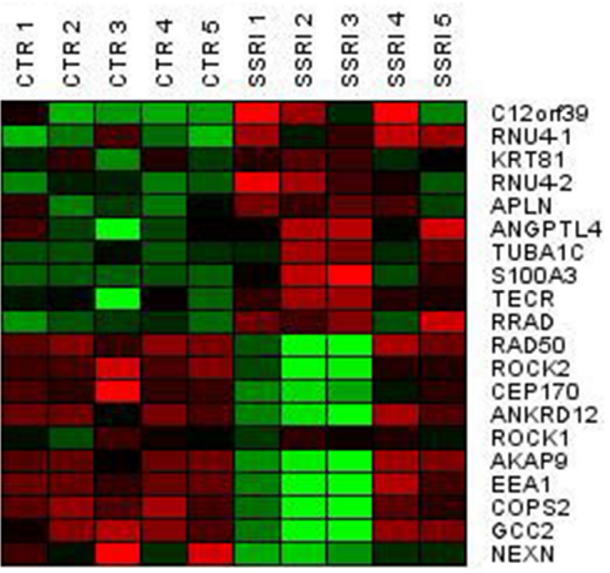

FIGURE 1 | Visualization of differentially expressed genes using hierarchical clustering of genes in depressed (A) and SSRI-treated (B) vs. control fetal placentas.

Table 5 | Enriched ingenuity pathway analysis (IPA) categories including differentially expressed genes in the depressed group.

\begin{tabular}{|c|c|c|}
\hline IPA network top 5 & Genes & IPA score \\
\hline
\end{tabular}

Cell cycle, cancer, connective

CHD1 $(p=0.026) ; C H D 9(p=0.026) ;$ DNAJC10 $(p=0.028)$; FZD6

tissue disorders

$(p=0.018) ;$ HOMER1 $(p=0.048) ; N 4 B P 2 L 2(p=0.029) ; N I P B L$

$(p=0.046) ;$ PTBP2 $(p=0.041) ;$ SKIV2L2 $(p=0.041) ;$ SNAPC1

$(p=0.046)$, YEATS4 $(p=0.026) ;$ ZNF638 $(p=0.035)$

Cellular movement,

hematological system development and function, immune cell T rafficking

Cardiovascular system development and function, organismal development, visual system development and function
CENPE $(p=0.026) ;$ COPS2 $(p=0.008) ;$ LUC7L3 $(p=0.026)$; $(p=0.023) ;$ SENP6 $(p=0.021) ;$ SENP7 $(p=0.023) ;$ STXBP3

$(p=0.026) ; \operatorname{ZNF146}(p=0.028)$

APOC1 $(p=0.034) ; \operatorname{CHRM3}(p=0.021) ; D E K(p=0.039) ; D N M 1 L$

(0.048); ERBB2IP (0.025); PGF $(p=0.013) ; \operatorname{PPP1R12A~}(p=0.021)$;

RALGPS2 $(p=0.028) ; \operatorname{RIF1}(p=0.039) ; \operatorname{ROCK2}(p=0.021)$

Molecular transport, RNA

trafficking, connective tissue

disorders

$D G K H(p=0.026) ;$ FNBP1L $(p=0.046) ; \operatorname{KTN1}(p=0.021) ;$ NKTR

$(p=0.046) ;$ RNF19A $(p=0.048) ;$ THOC2 $(p=0.028)$

Table 6 | Canonical pathway analysis of the depressed group.

\section{Canonical pathway}

Actin nucleation by ARP-WASP complex

RhoA signaling

VEGF signaling

Protein kinase A signaling

1D-myo-inositol Hexakisphosphate Biosynthesis V (from Ins(1,3,4)P3)

\section{Genes}

PPP1R12A, ROCK1, ROCK2

KTN1, PPP1R12A, ROCK1, ROCK 2

$P G F, R O C K 1, R O C K 2$

AKAP9, ANAPC4, PDE3B, PPP1R12A, ROCK1, ROCK2

ITPK1
$P$-value

0.003

0.029

0.011

0.011

0.015 
Table 7 | Significantly up and down regulated genes in the control vs. SSRI groups ( $-=$ reduction in expression levels).

\begin{tabular}{|c|c|c|c|}
\hline Gene symbol & Gene name & Probe ID & Log2 fold change \\
\hline C12orf39 & chromosome 12 open reading frame 39 & 7954398 & 1.274830514 \\
\hline FLJ34503 & hypothetical FLJ34503 & 8121569 & 1.266115442 \\
\hline RNU4-1 /// RNU4-1B & RNA, U4 small nuclear 1 /// RNA, U4 small nuclear 1B & 7967030 & 0.911924177 \\
\hline KRTAP19-8 & keratin associated protein 19-8 & 8069876 & 0.821169613 \\
\hline OR2A7 /// OR2A4 /// LOC728377 & $\begin{array}{l}\text { olfactory receptor, family } 2 \text {, subfamily } A \text {, member } 7 \text { /// olfactory receptor, } \\
\text { family } 2 \text {, subfamily A, member } 4 \text { /// similar to rho guanine nucleotide } \\
\text { exchange factor } 5\end{array}$ & 8143633 & 0.791137617 \\
\hline KRT81 & keratin 81 & 7963353 & 0.778243623 \\
\hline OR2A7 /// OR2A4 /// LOC728377 & $\begin{array}{l}\text { olfactory receptor, family } 2 \text {, subfamily } A \text {, member } 7 \text { /// olfactory receptor, } \\
\text { family } 2 \text {, subfamily A, member } 4 \text { /// similar to rho guanine nucleotide } \\
\text { exchange factor } 5\end{array}$ & 8129558 & 0.774018568 \\
\hline RNU4-2 & RNA, U4 small nuclear 2 & 7967028 & 0.707367007 \\
\hline- & - & 7899484 & 0.693169774 \\
\hline SERINC2 & serine incorporator 2 & 7899615 & 0.641601416 \\
\hline APLN & apelin & 8175016 & 0.632933192 \\
\hline ANGPTL4 & angiopoietin-like 4 & 8025402 & 0.61857093 \\
\hline TUBA1C & tubulin, alpha $1 \mathrm{c}$ & 7955179 & 0.558532616 \\
\hline- & - & 8139128 & 0.546472497 \\
\hline S100A3 & S100 calcium binding protein A3 & 7920278 & 0.543186629 \\
\hline LOC100127980 & hypothetical protein LOC100127980 & 8036302 & 0.540856558 \\
\hline TECR & trans-2,3-enoyl-CoA reductase & 8101622 & 0.539800494 \\
\hline SCARNA10 & small Cajal body-specific RNA 10 & 7953383 & 0.537535155 \\
\hline$R R A D$ & Ras-related associated with diabetes & 8001918 & 0.534226961 \\
\hline EFNA5 & ephrin-A5 & 8113433 & 0.533194259 \\
\hline CDC42EP1 & CDC42 effector protein (Rho GTPase binding) 1 & 8072817 & 0.529414661 \\
\hline PCTK1 & PCTAIRE protein kinase 1 & 8167103 & 0.528119471 \\
\hline SNORD116-16 & small nucleolar RNA, C/D box 116-16 & 7981980 & 0.525075622 \\
\hline- & - & 8130181 & 0.511027698 \\
\hline- & - & 7953128 & 0.508366155 \\
\hline ORMDL3 & ORM1-like 3 (S. cerevisiae) & 8014916 & 0.507840044 \\
\hline $\begin{array}{l}\text { ARHGEF5 /// ARHGEF5L /// } \\
\text { LOC728377 }\end{array}$ & $\begin{array}{l}\text { Rho guanine nucleotide exchange factor (GEF) } 5 \text { /// Rho guanine } \\
\text { nucleotide exchange factor (GEF) } 5 \text {-like /// similar to rho guanine } \\
\text { nucleotide exchange factor } 5\end{array}$ & 8136987 & 0.503949491 \\
\hline MAP4K5 & mitogen-activated protein kinase kinase kinase kinase 5 & 7978997 & -0.503225433 \\
\hline FANCL /// VRK2 & Fanconi anemia, complementation group L /// vaccinia related kinase 2 & 8052382 & -0.503353866 \\
\hline AHCTF1 & AT hook containing transcription factor 1 & 7925622 & -0.503946371 \\
\hline ZNF280D & zinc finger protein 280D & 7989159 & -0.505508381 \\
\hline SNX6 & sorting nexin 6 & 7978570 & -0.512758574 \\
\hline $\begin{array}{l}\text { CBWD3 /// CBWD5 /// CBWD6 /// } \\
\text { LOC728877 /// CBWD7 /// } \\
\text { LOC653510 /// CBWD2 }\end{array}$ & $\begin{array}{l}\text { COBW domain containing } 3 \text { /// COBW domain containing } 5 \text { /// COBW } \\
\text { domain containing } 6 \text { /// similar to COBW domain containing } 3 \text { /// COBW } \\
\text { domain containing } 7 / / / \text { similar to COBW domain containing } 1 / / / \mathrm{COBW} \\
\text { domain containing } 2\end{array}$ & 8155422 & -0.513922351 \\
\hline PHF2OL 1 & PHD finger protein 20-like 1 & 8148358 & -0.514646483 \\
\hline FAS & Fas (TNF receptor superfamily, member 6) & 7929032 & -0.527079798 \\
\hline METTL 14 & methyltransferase like 14 & 8097066 & -0.531709394 \\
\hline ZNF100 & zinc finger protein 100 & 8035808 & -0.534310441 \\
\hline $\begin{array}{l}\text { RGPD2 /// RGPD5 /// RGPD8 /// } \\
\text { RGPD3 /// RGPD4 /// RGPD6 /// } \\
\text { RGPD1 /// RANBP2 }\end{array}$ & $\begin{array}{l}\text { RANBP2-like and GRIP domain containing } 2 \text { /// RANBP2-like and GRIP } \\
\text { domain containing } 5 \text { /// RANBP2-like and GRIP domain containing } 8 \text { /// } \\
\text { RANBP2-like and GRIP domain containing } 3 \text { /// RANBP2-like and GRIP } \\
\text { domain containing } 4 \text { /// RANBP2-like and GRIP domain containing } 6 \text { /// } \\
\text { RANBP2-like and GRIP domain containing } 1 \text { /// RAN binding protein } 2\end{array}$ & 8044161 & -0.543369485 \\
\hline SHOC2 & soc-2 suppressor of clear homolog (C. elegans) & 7930470 & -0.550070146 \\
\hline IRAK1BP1 & interleukin-1 receptor-associated kinase 1 binding protein 1 & 8120826 & -0.550763514 \\
\hline VAMP7 & vesicle-associated membrane protein 7 & 8171041 & -0.554437451 \\
\hline
\end{tabular}


Table 7 | Continued

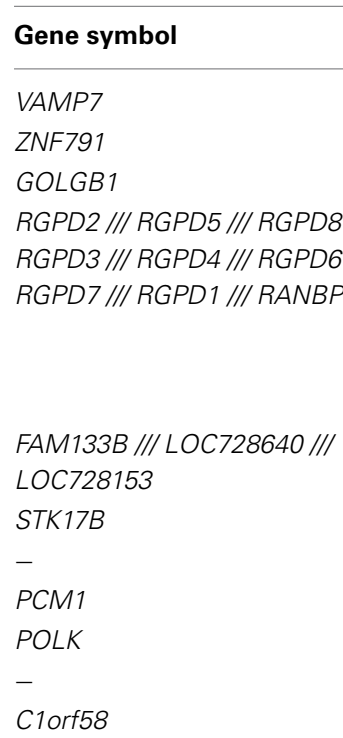

RGPD1 /// RGPD2 /// RGPD5 /// RGPD8 /// RGPD3 /// RGPD4 /// RGPD6 /// RGPD7 /// RANBP2

RGPD2 /// RGPD5 /// RGPD8 /// RGPD3 /// RGPD4 /// RGPD6 /// RGPD7 /// RGPD1 /// RANBP2

RANBP2
-
MNS1
DNAJC13
BDP1
NKTR
ARID4A
CBWD3 /// CBWD5 /// CBWD6 ///
CBWD7 /// LOC653510 ///
CBWD2 /// CBWD1

$B D P 1$

$-$

JMJD1C

ABCC9

C15orf5

LAMA4

FAM133B /// LOC728640

PRPF40A

ERGIC2

ZNF644

CCDC88A

\section{Gene name}

vesicle-associated membrane protein 7

zinc finger protein 791

golgin B1, golgi integral membrane protein

RANBP2-like and GRIP domain containing 2 /// RANBP2-like and GRIP domain containing 5 /// RANBP2-like and GRIP domain containing 8 /// RANBP2-like and GRIP domain containing 3 /// RANBP2-like and GRIP domain containing 4 /// RANBP2-like and GRIP domain containing 6 /// RANBP2-like and GRIP domain containing 7 /// RANBP2-like and GRIP domain containing $1 / / /$ RAN binding protein 2

family with sequence similarity 133 , member B /// family with sequence similarity 133, member B pseudogene /// similar to FAM133B protein serine/threonine kinase $17 \mathrm{~b}$

$-$

pericentriolar material 1

polymerase (DNA directed) kappa

chromosome 1 open reading frame 58

RANBP2-like and GRIP domain containing 1 /// RANBP2-like and GRIP domain containing 2 /// RANBP2-like and GRIP domain containing 5 /// RANBP2-like and GRIP domain containing 8 /// RANBP2-like and GRIP domain containing 3 /// RANBP2-like and GRIP domain containing 4 /// RANBP2-like and GRIP domain containing 6 /// RANBP2-like and GRIP domain containing 7 /// RAN binding protein 2

RANBP2-like and GRIP domain containing 2 /// RANBP2-like and GRIP domain containing 5 /// RANBP2-like and GRIP domain containing 8 /// RANBP2-like and GRIP domain containing 3 /// RANBP2-like and GRIP domain containing 4 /// RANBP2-like and GRIP domain containing 6 /// RANBP2-like and GRIP domain containing 7 /// RANBP2-like and GRIP domain containing $1 / / /$ RAN binding protein 2

RAN binding protein 2

$-$

meiosis-specific nuclear structural 1

DnaJ (Hsp40) homolog, subfamily C, member 13

B double prime 1, subunit of RNA polymerase III transcription initiation factor IIIB

natural killer-tumor recognition sequence

AT rich interactive domain $4 \mathrm{~A}$ (RBP1-like)

COBW domain containing $3 / / / \mathrm{COBW}$ domain containing $5 / / / \mathrm{COBW}$ domain containing $6 / / /$ COBW domain containing $7 / / /$ similar to COBW domain containing $1 / / /$ COBW domain containing 2 /// COBW domain containing 1

B double prime 1, subunit of RNA polymerase III transcription initiation factor IIIB

$-$

jumonji domain containing $1 \mathrm{C}$

ATP-binding cassette, sub-family C (CFTR/MRP), member 9

chromosome 15 open reading frame 5

laminin, alpha 4

family with sequence similarity 133 , member B /// family with sequence similarity 133, member B pseudogene

PRP40 pre-mRNA processing factor 40 homolog A (S. cerevisiae)

ERGIC and golgi 2

zinc finger protein 644

coiled-coil domain containing $88 \mathrm{~A}$

\section{Probe ID}

8176962

8026007

8089930

8044304

Log2 fold change

$-0.554437451$

$-0.55599566$

$-0.559994665$

$-0.562605545$

8105504

$-0.56577534$

8057887

8054532

8144812

8106303

8147650

7909931

8054414

$-0.565889797$

$-0.568088762$

$-0.574364755$

$-0.576549694$

$-0.578295577$

$-0.580015227$

$-0.582592072$

8054676

$-0.586951747$

8044263

8054557

7989146

8082688

8106025

8079079

7974621

8161575

-0.589348972
-0.592061813
-0.595349364
-0.601103633
-0.601882298
-0.602491778
-0.602522967
-0.605839737

8177560

$-0.608777219$

7942645

7933877

7961710

7990636

8128991

8055978

$-0.611731094$

$-0.612753894$

$-0.613240551$

$-0.631000244$

$-0.636829539$

$-0.63846971$

8055913

$-0.641694474$

7962013

$-0.65241833$

7917604

8052269
$-0.664132951$

$-0.673093507$ 
Table 7 | Continued

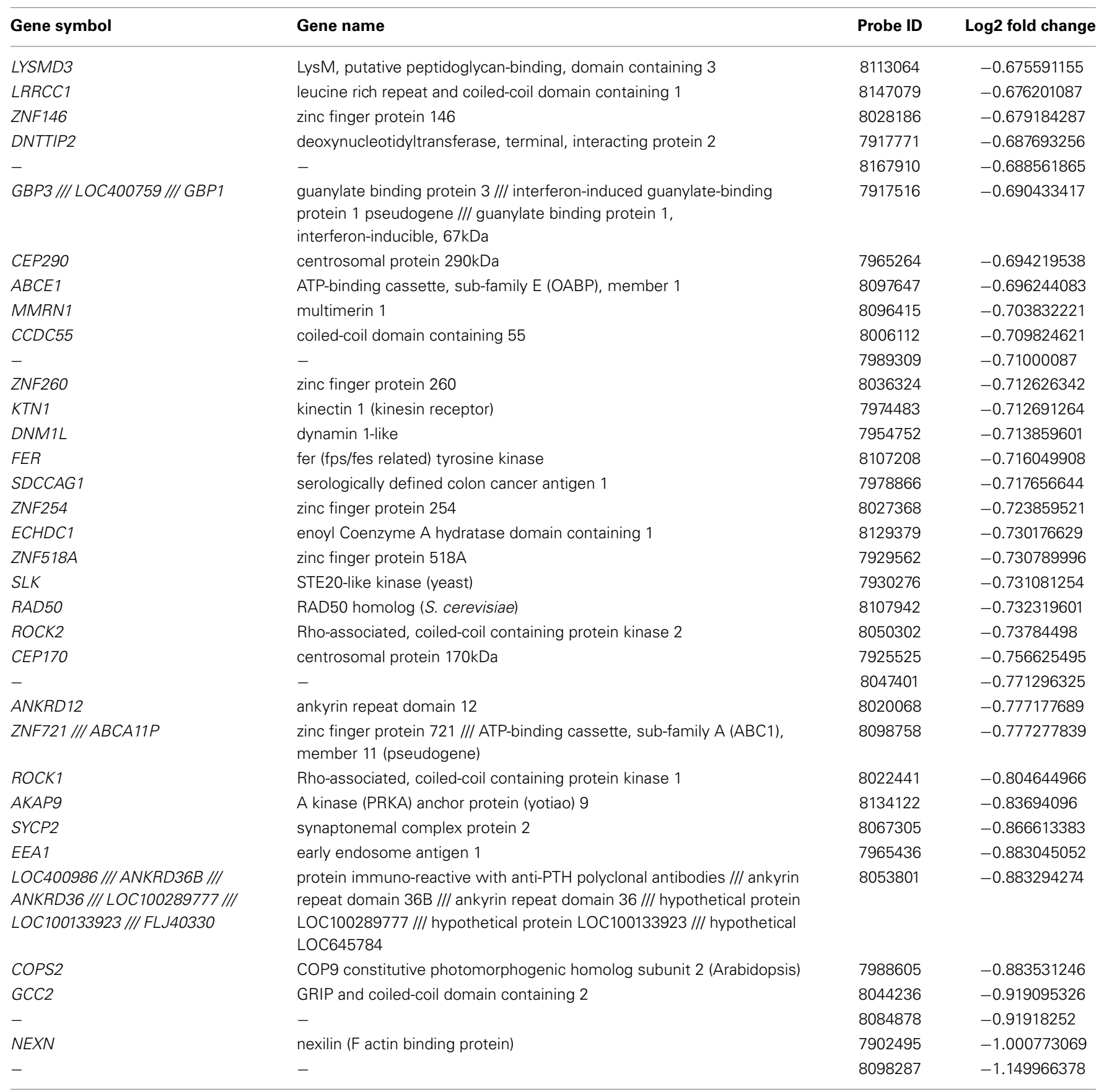

expressed in antidepressant-treated women. Only 20 genes were overlapping between depressed women and women on antidepressant treatment. Among the genes we chose for validation, only 2 were validated with qPCR for depressed women. In the antidepressant-treated women, 6 genes were validated, indicating a more robust effect in alterations of these genes due to antidepressant treatment during pregnancy.

Antenatal depression is a relatively heterogeneous condition with different causes (primary or secondary to somatic disease) and differential degree of endocrine disturbances. Furthermore, women with antenatal depression may also differ between the pilot microarray and the validation study as to depression severity and duration of the depressive episode. These factors may have precluded the possibility to confirm the microarray findings, and it is a major limitation that not all women in the validation part of the study were diagnosed by a structured psychiatric interview. As depression per se has effects on perinatal outcomes such as birth weight and gestational age (Chambers et al., 1996), suggesting that placental function is altered, further studies in more homogeneous women (and with larger sample sizes) of depression are warranted. In addition, women on antidepressant treatment during pregnancy possibly may have had a more severe depression, 
Table 8 | Significantly up- and down-regulated top molecules in the control vs. SSRI group (- = reduction in expression levels).

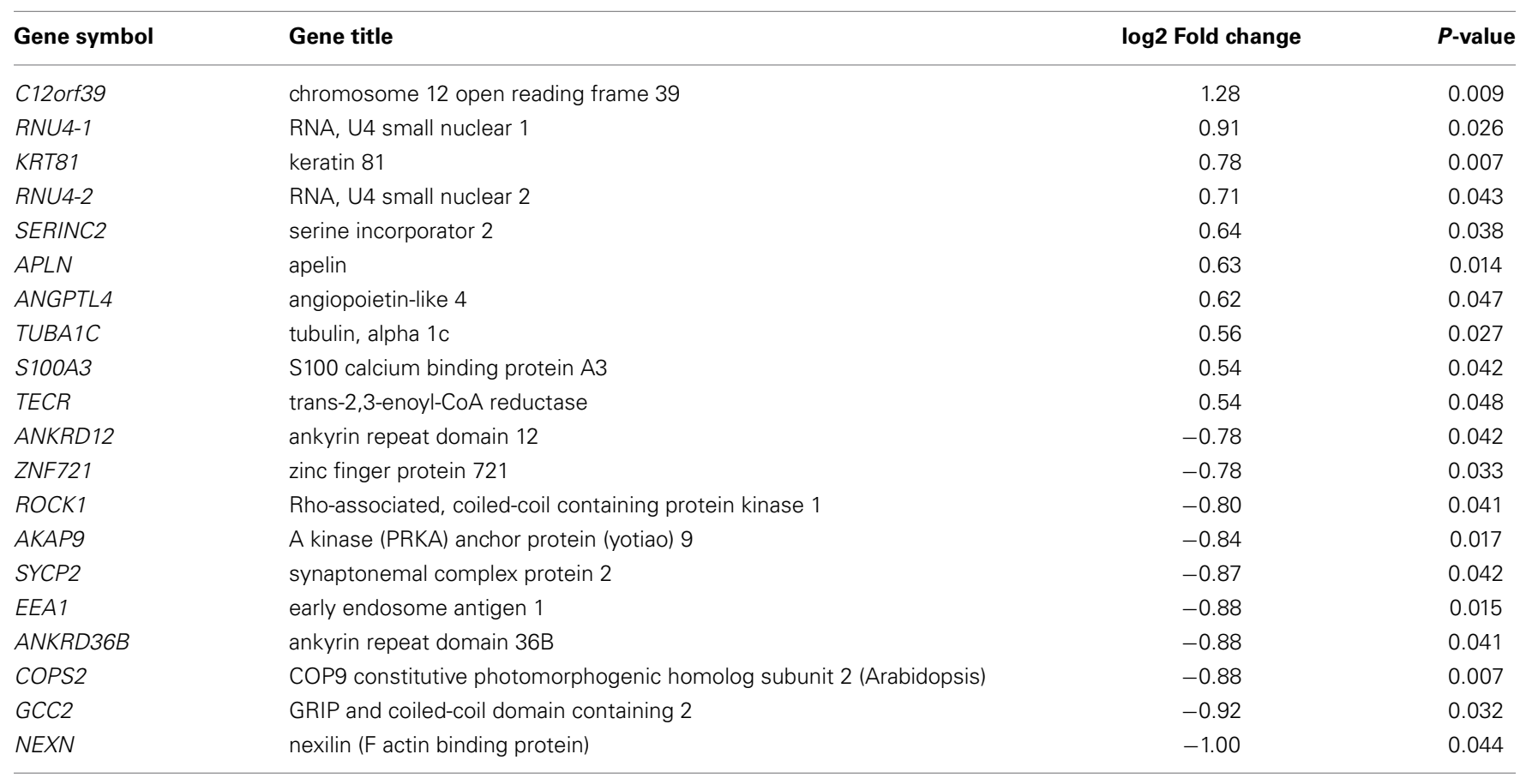

Table 9 | Enriched ingenuity pathway analysis (IPA) categories including differentially expressed genes in the SSRI group.

\begin{tabular}{|c|c|c|}
\hline IPA network top 5 & Genes & IPA score \\
\hline $\begin{array}{l}\text { Infectious disease, cellular } \\
\text { assembly and organization, } \\
\text { cellular function and maintenance }\end{array}$ & $\begin{array}{l}\text { ARHGEF5 }(p=0.017) ; \operatorname{ARID4A}(p=0.041) ; \operatorname{CDK16}(p=0.023) \\
\text { DNAJC13 }(p=0.036) ; \operatorname{EFNA5}(p=0.027) ; \operatorname{GBP} 1(p=0.027) \\
\text { IRAK1BP1 }(p=0.022) ; \operatorname{KTN1}(p=0.016) ; \operatorname{MMRN1}(p=0.045) \\
\text { NKTR }(p=0.017) ; \text { PRPF40A }(p=0.017) ; \operatorname{RANBP2}(p=0.034) \\
\text { SNX6 }(p=0.033)\end{array}$ & 13 \\
\hline $\begin{array}{l}\text { Cell death and survival, } \\
\text { inflammatory response, cellular } \\
\text { movement }\end{array}$ & $\begin{array}{l}\text { ANKRD12 }(p=0.042) ; \operatorname{BDP} 1(p=0.038) ; \operatorname{CCDC} 88 A(p=0.048) \\
\text { DNM1L }(p=0.015) ; \text { FANCL }(p=0.048) ; \text { FER }(p=0.042) ; J M J D 1 C \\
(p=0.028) ; \text { ROCK2 }(p=0.027) ; \text { S100A3 }(p=0.042)\end{array}$ & 9 \\
\hline $\begin{array}{l}\text { Cardiovascular disease, skeletal } \\
\text { and muscular disorders, } \\
\text { cardiovascular system } \\
\text { development and function }\end{array}$ & $N E X N(p=0.044)$ & 2 \\
\hline
\end{tabular}

since continued treatment apparently was needed, and that this effect is reflected in the gene expression pattern. However, it is also possible that alterations in placental gene expression already occur because of the antenatal depression, but become (more) apparent, when antidepressants are used. Although several alterations in the gene expression of the fetal placenta were found, it remains to establish if these alterations are found in the fetus as well.

When the microarray was validated with a larger sample-size, ROCK2 was down-regulated in both depressed and SSRI-treated women. ROCK1 and ROCK2 are part of the Rho-associated coiled-coil kinase family (Nakagawa et al., 1996; Amano et al., 
Table 10 | Canonical pathway analysis of the SSRI group.

\begin{tabular}{lll}
\hline Canonical pathway & Genes & $P$-value \\
\hline Ephrin A signaling & $E F N A 5, R O C K 1, R O C K 2$ & 0.001 \\
RhoA signaling & $C D C 42 E P 1, K T N 1, R O C K 1, R O C K 2$ & 0.002 \\
PEDF signaling & $F A S, R O C K 1, R O C K 2$ & 0.004 \\
Breast cancer regulation by Stathmin 1 & $A R H G E F 5, R O C K 1, R O C K 2, T U B A 1 C$ & 0.012 \\
Signaling by Rho Family GTPases & ARHGEF5,CDC42EP1, ROCK1, ROCK2 & 0.021
\end{tabular}

Table 11 | Genes commonly altered in depressed and SSRI groups compared with controls. (- = reduction in expression levels).

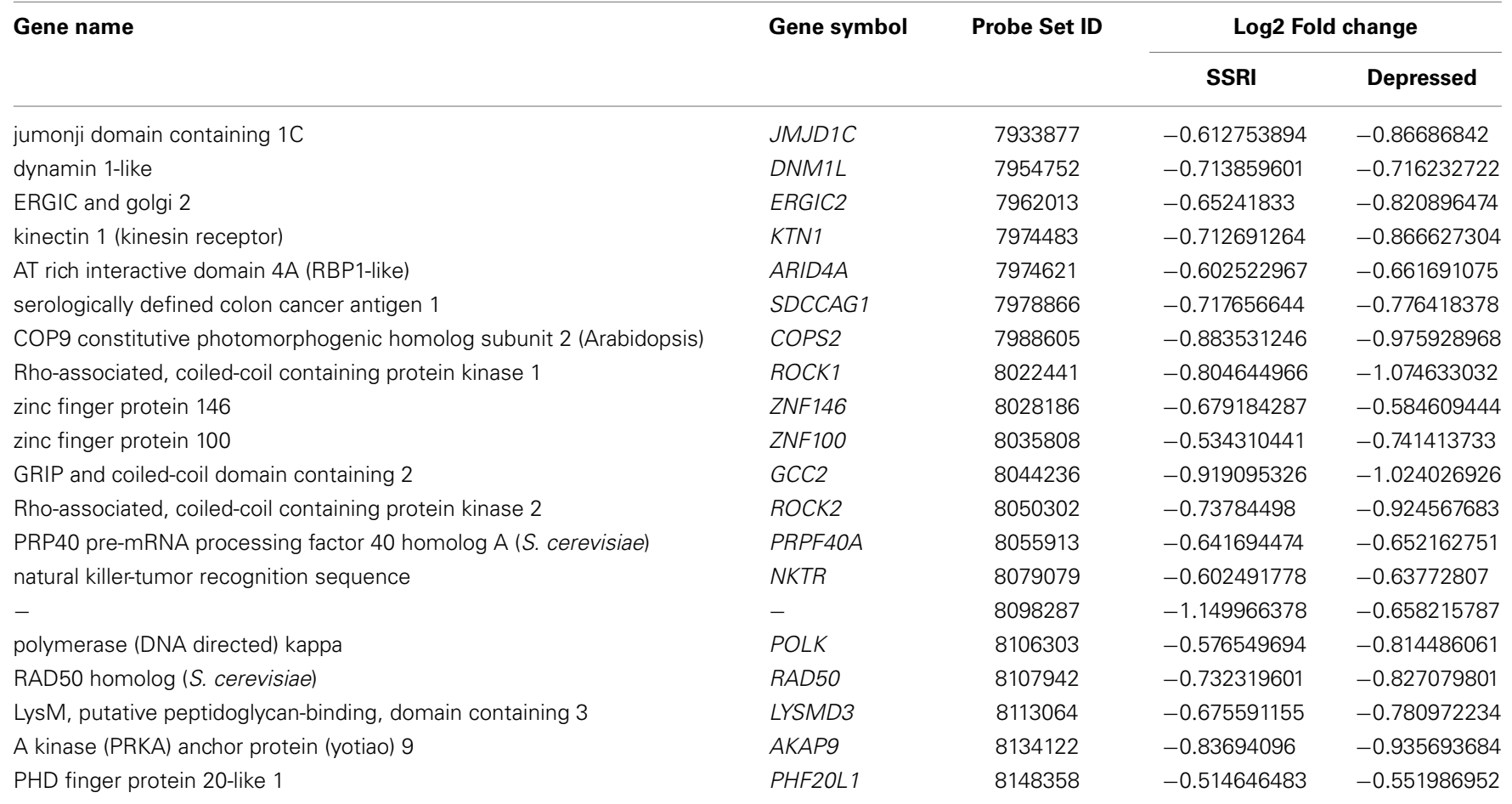
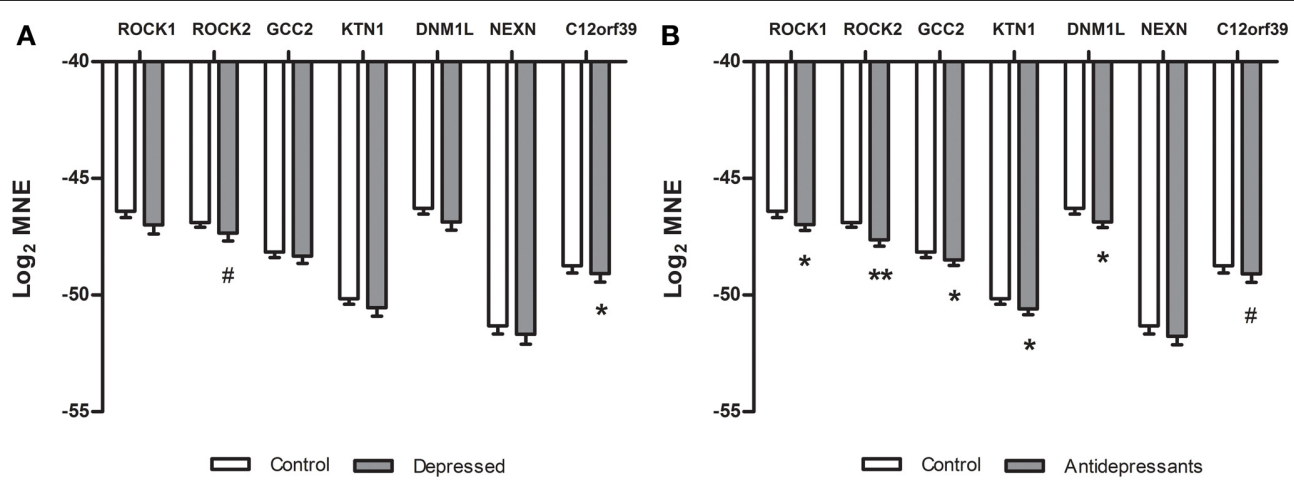

FIGURE 2 | Differences in gene expression (qPCR) between subsets in the validation study of the microarray data. Log2 mean normalized expression (MNE) is shown for the ROCK1, ROCK2, GCC2,

KTN1, DNM1L, NEXN, and C12orf39 genes in depressed (A) and SSRI women (B). (A) ${ }^{*} P=0.05,{ }^{*} P=0.08$, (B) ${ }^{*} P \leq 0.05, * * P<0.01$, ${ }^{\#} P=0.07$.

2000) and are downstream effectors of RhoA-GTP. Rho-ROCK signaling pathways are involved in the regulation of actin cytoskeleton, cell migration and proliferation (Schofield and Bernard, 2013). In mice, ROCK1 is highly expressed in the lung, liver, spleen, kidney and testis, whereas ROCK2 is most abundant in the brain and heart (Nakagawa et al., 1996; Di et al., 2000; Wei et al., 2001). The role of the Rho/ROCK family in cardiovascular diseases has been extensively studied (Shi and Wei, 2013). Cardiac 
malformations (Diav-Citrin et al., 2008), including pulmonary hypertension (Chambers et al., 1996, 2006; Källén and Olausson, 2008; Kieler et al., 2012), have also been reported in the SSRIexposed offspring. In the present study we found that ROCK2 was down-regulated in antidepressant-exposed placentas (and to lesser extent in placentas of depressed women). Moreover, IPA analysis revealed that SSRI treatment affects the "Cardiovascular Disease, Skeletal and Muscular Disorders, Cardiovascular System Development and Function" network. Furthermore, it seems that the use of SSRIs intensifies the alterations in ROCK2 expression compared to depression. Due to lowered ROCK2 expression found in the fetal placenta of antidepressant-treated women, it is tempting to speculate that a normal expression of ROCK2 in placenta is important for a normal function of the cardiovascular system in the fetus.

Interestingly, we also found that NEXN was down-regulated in antidepressant-treated women. NEXN is a Z-disk gene which is associated with dilated cardiomyopathy (Hassel et al., 2009). Hence, further studies are necessary to investigate the effects of down-regulated placental NEXN and ROCK2 on the development of the cardiovascular system in the fetus.

Besides the role of the Rho kinase pathway in cardiovascular diseases, a role has also been proposed for the modulation of the placental vasculature. Although expression of ROCK1 and ROCK2 was not different, a higher RhoA mRNA expression was found in placentae from women who suffered from preeclampsia compared with placentae from those that were normotensive (Friel et al., 2008). Interestingly, the use of antidepressants have been associated with an increased risk for preeclampsia (Palmsten et al., 2012). In addition, normal ROCK1 and ROCK2 activity is required for normal inner cell mass morphogenesis, which is of importance for successful fetal development (Laeno et al., 2013). These data indicate that antidepressant use, mainly SSRI, during pregnancy may influence pregnancy complications and fetal development, and that ROCK 1 and ROCK 2 may be involved with these processes.

Another gene that was down-regulated in depressed women and to a lesser extent in antidepressant-treated women is the C12orf39. C12orf39 is mainly expressed in the placenta and brain, suggesting that C12orf39 may function in these active secretory tissues (Wan et al., 2010). With regard to its function, C12orf39 is mainly extracellular and located in the villous trophoblasts. Trophoblasts are important in exchanges between the fetus and the mother and possess endocrine activity, releasing hormones that are important in the homoeostasis of pregnancy (Lunghi et al., 2007). In addition, trophoblasts are involved with the secretion of placental growth hormone and are related to the development of the placenta (Zeck et al., 2008). Together, these findings suggest that C12orf39 is implicated in the regulation of placenta development by its role in the biological functions of the trophoblasts and that antenatal depression during pregnancy may influence this development. Of interest is the fact that in antidepressant-treated women the effect is no longer significant, which may indicate that antidepressants may restore the effects of the depression-induced down-regulation of C12of39.

GCC2 is a peripheral membrane protein localized to the trans-Golgi network (Luke et al., 2003) which is involved in the maintenance of Golgi structure or transport vesicle tethering (Brown et al., 2011). More research is needed to investigate the effects of altered gene expression of GCC2 in the placenta on the developing fetus.

Similarly, KTN1 encodes the full kinectin which is found in the endoplasmic reticulum and is responsible for the transport of vesicles along microtubules. KTN1 is mainly expressed in the brain, liver, ovarian, and hematopoietic cells (Tran et al., 2002; Bai et al., 2006). Of interest is that kinectin can interact with RhoA (Hotta et al., 1996), and that the RhoA signaling pathway is affected in the depressed and antidepressant-treated women. As described before normal RhoA signaling is important to prevent pregnancy complications. Possible consequences for the fetus due to the down-regulation of KTN1 in the placenta remains to be investigated.

The last gene that was validated was $D N M 1 L$, which is a GTPase regulating the mitochondrial fission. In mice it was shown that ablation of the DNM1L gene induced defects in trophoblast giant cells and cardiomyocytes (Wakabayashi et al., 2009). Moreover, brain-specific DNM1L ablation caused developmental defects in the cerebellum (Wakabayashi et al., 2009). Although these results were found in knockout mice it is tempting to speculate that the down-regulation of the DNM1L found in the antidepressant-treated women might have an effect on embryonic and brain development as well. However, again, this effect remains to be established.

Despite the strengths of our study, such as the longitudinal nature of the study and the information on the state of the mothers mood at multiple time points, some limitations need to be discussed. First, we investigated alterations in gene expression of the fetal side of the placenta due to antenatal depression and antidepressant treatment. The results of this study may give us an indication on altered pathways in the placenta. However, the placenta is a separate organ and is not part of the fetus itself, therefore findings need to be replicated in the developing fetus. In humans this is not easily feasible therefore experiments are ongoing in a rodent study. Second, antenatal depression is a relatively heterogeneous condition and outcome of diagnoses and treatment plans (before the women entered the study) were diagnosed by different doctors which may have biased the outcome. As a result dosages and types of medication may not have been appropriate for the diagnosed depression. Nevertheless, all women did undergo the EPDS screening providing comparable data between the groups concerning the mood state at different time points during (and after) pregnancy. Third, in the validation study we included different types of antidepressants, although they were mainly SSRIs, this may have influenced the outcome of the gene expression in the SSRI treatment group.

In conclusion, gene expression in the fetal placenta is altered by antenatal depression and SSRI treatment. As more placental genes alterations were validated in a larger subset of SSRI-treated women compared to those with antenatal depression we conclude that for these subset of genes, the effects of SSRI-intake during pregnancy are more robust. It remains to be established how these differentially affected genes influence the development of the child, and whether these differences are found in the fetus as well. 


\section{ACKNOWLEDGMENTS}

This work was supported by grants from the Swedish Research Council (Grant No. K2014-54X-20642-07-4), the Marianne and Marcus Wallenberg Foundation (2010:0031), KI fonder research (2013fobi37758), and the Swedish Society of Medicine (SLS-303881 \& SLS-384001).

\section{SUPPLEMENTARY MATERIAL}

The Supplementary Material for this article can be found online at: http://www.frontiersin.org/journal/10.3389/fncel.2014. 00465/abstract

\section{REFERENCES}

Alwan, S., Reefhuis, J., Rasmussen, S. A., and Friedman, J. M. (2011). Patterns of antidepressant medication use among pregnant women in a United States population. J. Clin. Pharmacol. 51, 264-270. doi: 10.1177/0091270010373928

Amano, M., Fukata, Y., and Kaibuchi, K. (2000). Regulation and functions of Rhoassociated kinase. Exp. Cell Res. 261, 44-51. doi: 10.1006/excr.2000.5046

American Psychiatric Association. (2013). Diagnostic and Statistical Manual of Mental Disorders, 5th Edn. Arlington, TX: American Psychiatric Publishing.

Andrade, S. E., Raebel, M. A., Brown, J., Lane, K., Livingston, J., Boudreau, D., et al. (2008). Use of antidepressant medications during pregnancy: a multisite study. Am. J. Obstet. Gynecol. 198, 194-195. doi: 10.1016/j.ajog.2007.07.036

Babenko, O., Kovalchuk, I., and Metz, G. A. (2015). Stress-induced perinatal and transgenerational epigenetic programming of brain development and mental health. Neurosci. Biobehav. Rev. 48C, 70-91. doi: 10.1016/j.neubiorev.2014.11.013

Bai, J. Z., Mon, Y., and Krissansen, G. W. (2006). Kinectin participates in microtubule-dependent hormone secretion in pancreatic islet beta-cells. Cell Biol. Int. 30, 885-894. doi: 10.1016/j.cellbi.2006.06.008

Barker, E. D., Jaffee, S. R., Uher, R., and Maughan, B. (2011). The contribution of prenatal and postnatal maternal anxiety and depression to child maladjustment. Depress. Anxiety 28, 696-702. doi: 10.1002/da.20856

Benjamini, Y., and Hochberg, Y. (1995). Controlling the false discovery rate: a practical and powerful approach to multiple testing. J. R. Stat. Soc. Series B Methodol. 57, 289-300.

Bergvink, V., Kooistra, L., Lambregtse-van den Berg, M. P., Wijnen, H., Bunevicius, R., van Baar, A., et al. (2011). Validation of the Edinburgh depression scale during pregnancy. J. Psychosom. Res. 70, 385-389. doi: 10.1016/j.jpsychores.2010.07.008

Bonnin, A., Goeden, N., Chen, K., Wilson, M. L., King, J., Shih, J. C., et al. (2011). A transient placental source of serotonin for the fetal forebrain. Nature 472, 347-350. doi: 10.1038/nature09972

Bourke, C. H., Stowe, Z. N., and Owens, M. J. (2014). Prenatal antidepressant exposure: clinical and preclinical findings. Pharmacol. Rev. 66, 435-465. doi: 10.1124/pr.111.005207

Brown, F. C., Schindelhaim, C. H., and Pfeffer, S. R. (2011). GCC185 plays independent roles in Golgi structure maintenance and AP-1-mediated vesicle tethering. J. Cell Biol. 194, 779-787. doi: 10.1083/jcb.201104019

Chambers, C. D., Hernandez-Diaz, S., Van Marter, L. J., Werler, M. M., Louik, C. Jones, K. L., et al. (2006). Selective serotonin-reuptake inhibitors and risk of persistent pulmonary hypertension of the newborn. N. Engl. J. Med. 354, 579-587. doi: 10.1056/NEJMoa052744

Chambers, C. D., Johnson, K. A., Dick, L. M., Felix, R. J., and Jones, K. L. (1996). Birth outcomes in pregnant women taking fluoxetine. N. Engl. J. Med. 335, 1010-1015. doi: 10.1056/NEJM199610033351402

Clements, C. C., Castro, V. M., Blumenthal, S. R., Rosenfield, H. R., Murphy, S. N., Fava, M., et al. (2014). Prenatal antidepressant exposure is associated with risk for attention-deficit hyperactivity disorder but not autism spectrum disorder in a large health system. Mol. Psychiatry. doi: 10.1038/mp.2014.90 [Epub ahead of print].

Croen, L. A., Grether, J. K., Yoshida, C. K., Odouli, R., and Hendrick, V. (2011). Antidepressant use during pregnancy and childhood autism spectrum disorders. Arch. Gen. Psychiatry 68, 1104-1112. doi: 10.1001/archgenpsychiatry.2011.73

Di, C. F., Imarisio, S., Hirsch, E., Broccoli, V., Bulfone, A., Migheli, A., et al. (2000). Defective neurogenesis in citron kinase knockout mice by altered cytokinesis and massive apoptosis. Neuron 28, 115-127. doi: 10.1016/S08966273(00)00090-8

Diav-Citrin, O., Shechtman, S., Weinbaum, D., Arnon, J., di Gianantonio, E., Clementi, M., et al. (2008). Paroxetine and fluoxetine in pregnancy: a multicenter, prospective, controlled study. Reprod. Toxicol. 20, 459. doi: 10.1111/j.13652125.2008.03261.x

Field, T. (2011). Prenatal depression effects on early development: a review. Infant Behav. Dev. 34, 1-14. doi: 10.1016/j.infbeh.2010.09.008

Field, T., Diego, M., Dieter, J., Hernandez-Reif, M., Schanberg, S., Kuhn, C., et al. (2004). Prenatal depression effects on the fetus and the newborn. Infant Behav. Dev. 27, 216-229. doi: 10.1016/j.infbeh.2003.09.010

Friel, A. M., Hynes, P. G., Sexton, D. J., Smith, T. J., and Morrison, J. J. (2008). Expression levels of mRNA for Rho A/Rho kinase and its role in isoprostaneinduced vasoconstriction of human placental and maternal vessels. Reprod. Sci. 15, 179-188. doi: 10.1177/1933719107310306

Gentile, S. (2005). SSRIs in pregnancy and lactation: emphasis on neurodevelopmental outcome. CNS Drugs 19, 623-633. doi: 10.2165/00023210-20051907000004

Gibson, J., McKenzie-McHarg, K., Shakespeare, J., Price, J., and Gray, R. (2009). A systematic review of studies validating the Edinburgh Postnatal Depression Scale in antepartum and postpartum women. Acta Psychiatr. Scand. 119, 350-364. doi: 10.1111/j.1600-0447.2009.01363.x

Hassel, D., Dahme, T., Erdmann, J., Meder, B., Huge, A., Stoll, M., et al. (2009). Nexilin mutations destabilize cardiac Z-disks and lead to dilated cardiomyopathy. Nat. Med. 15, 1281-1288. doi: 10.1038/nm.2037

Hay, D. F., Pawlby, S., Waters, C. S., Perra, O., and Sharp, D. (2010). Mothers' antenatal depression and their children's antisocial outcomes. Child Dev. 81, 149-165. doi: 10.1111/j.1467-8624.2009.01386.x

Helmestam, M., Andersson, H., Stavreus-Evers, A., Brittebo, E., and Olovsson, M. (2012). Tamoxifen modulates cell migration and expression of angiogenesisrelated genes in human endometrial endothelial cells. Am. J. Pathol. 180, 2527-2535. doi: 10.1016/j.ajpath.2012.02.026

Hostetter, A., Stowe, Z. N., Strader, J. R. Jr., McLaughlin, E., and Llewellyn, A. (2000). Dose of selective serotonin uptake inhibitors across pregnancy: clinical implications. Depress. Anxiety 11, 51-57. doi: 10.1002/(SICI)15206394(2000) 11:2<51::AID-DA1>3.0.CO;2-R

Hotta, K., Tanaka, K., Mino, A., Kohno, H., and Takai, Y. (1996). Interaction of the Rho family small $G$ proteins with kinectin, an anchoring protein of kinesin motor. Biochem. Biophys. Res. Commun. 225, 69-74. doi: 10.1006/bbrc. 1996.1132

Hsiao, E. Y., and Patterson, P. H. (2012). Placental regulation of maternalfetal interactions and brain development. Dev. Neurobiol. 72, 1317-1326. doi: $10.1002 /$ dneu. 22045

Irizarry, R. A., Hobbs, B., Collin, F., Beazer-Barclay, Y. D., Antonellis, K. J., Scherf, U., et al. (2003). Exploration, normalization, and summaries of high density oligonucleotide array probe level data. Biostatistics 4, 249-264. doi: 10.1093/biostatistics/4.2.249

Källén, B., and Olausson, P. O. (2008). Maternal use of selective serotonin reuptake inhibitors and persistent pulmonary hypertension of the newborn. Pharmacoepidemiol. Drug Saf. 17, 801-806. doi: 10.1002/pds.1570

Kieler, H., Artama, M., Engeland, A., Ericsson, O., Furu, K., Gissler, M., et al. (2012). Selective serotonin reuptake inhibitors during pregnancy and risk of persistent pulmonary hypertension in the newborn: population based cohort study from the five Nordic countries. BMJ 344:d8012. doi: 10.1136/bmj. d 8012

Laeno, A. M., Tamashiro, D. A., and Alarcon, V. B. (2013). Rho-associated kinase activity is required for proper morphogenesis of the inner cell mass in the mouse blastocyst. Biol. Reprod. 89, 122. doi: 10.1095/biolreprod.113.109470

Li, C., and Wong, W. H. (2001). Model-based analysis of oligonucleotide arrays: expression index computation and outlier detection. Proc. Natl. Acad. Sci. U.S.A. 98, 31-36. doi: 10.1073/pnas.98.1.31

Loughhead, A. M., Fisher, A. D., Newport, D. J., Ritchie, J. C., Owens, M. J., DeVane, C. L., et al. (2006). Antidepressants in amniotic fluid: another route of fetal exposure. Am. J. Psychiatry 163, 145-147. doi: 10.1176/appi.ajp. 163.1.145

Luke, M. R., Kjer-Nielsen, L., Brown, D. L., Stow, J. L., and Gleeson, P. A. (2003). GRIP domain-mediated targeting of two new coiled-coil proteins, GCC 88 and GCC185, to subcompartments of the trans-Golgi network. J. Biol. Chem. 278, 4216-4226. doi: 10.1074/jbc.M210387200 
Lunghi, L., Ferretti, M. E., Medici, S., Biondi, C., and Vesce, F. (2007). Control of human trophoblast function. Reprod. Biol. Endocrinol. 5:6. doi: 10.1186/14777827-5-6

Malm, H., Artama, M., Brown, A. S., Gissler, M., Gyllenberg, D., Hinkka-YliSalomaki, S., et al. (2012). Infant and childhood neurodevelopmental outcomes following prenatal exposure to selective serotonin reuptake inhibitors: overview and design of a Finnish Register-Based Study (FinESSI). BMC Psychiatry 12:217. doi: 10.1186/1471-244X-12-217

Miller, L. J., and LaRusso, E. M. (2011). Preventing postpartum depression. Psychiatr. Clin. North Am. 34, 53-65. doi: 10.1016/j.psc.2010.11.010

Muller, P. Y., Janovjak, H., Miserez, A. R., and Dobbie, Z. (2002). Processing of gene expression data generated by quantitative real-time RT-PCR. Biotechniques 32, 1372-1379.

Nakagawa, O., Fujisawa, K., Ishizaki, T., Saito, Y., Nakao, K., and Narumiya, S. (1996). ROCK-I and ROCK-II, two isoforms of Rho-associated coiled-coil forming protein serine/threonine kinase in mice. FEBS Lett. 392, 189-193. doi: 10.1016/0014-5793(96)00811-3

O'Keane, V., and Marsh, M. S. (2007). Depression during pregnancy. BMJ 334, 1003-1005. doi: 10.1136/bmj.39189.662581.55

Olivier, J. D., Åkerud, H., Kaihola, H., Pawluski, J. L., Skalkidou, A., Hogberg, U., et al. (2013). The effects of maternal depression and maternal selective serotonin reuptake inhibitor exposure on offspring. Front. Cell Neurosci. 7:73. doi: 10.3389/fncel.2013.00073

Olivier, J. D., Akerud, H., and Sundström-Poromaa, I. (2014). Antenatal depression and antidepressants during pregnancy: unraveling the complex interactions for the offspring. doi: 10.1016/j.ejphar.2014.07.049 [Epub ahead of print].

Palmsten, K., Setoguchi, S., Margulis, A. V., Patrick, A. R., and Hernandez-Diaz, S. (2012). Elevated risk of preeclampsia in pregnant women with depression: depression or antidepressants? Am. J. Epidemiol. 175, 988-997. doi: 10.1093/aje/kwr394

Pawlby, S., Hay, D. F., Sharp, D., Waters, C. S., and O'Keane, V. (2009). Antenatal depression predicts depression in adolescent offspring: prospective longitudinal community-based study. J. Affect. Disord. 113, 236-243. doi: 10.1016/j.jad.2008.05.018

Pearson, R. M., Evans, J., Kounali, D., Lewis, G., Heron, J., Ramchandani, P. G., et al. (2013). Maternal depression during pregnancy and the postnatal period: risks and possible mechanisms for offspring depression at age 18 years. JAMA Psychiatry 70, 1312-1319. doi: 10.1001/jamapsychiatry.2013.2163

Rai, D., Lee, B. K., Dalman, C., Golding, J., Lewis, G., and Magnusson, C. (2013). Parental depression, maternal antidepressant use during pregnancy, and risk of autism spectrum disorders: population based case-control study. $B M J$ 346:f2059. doi: 10.1136/bmj.f2059

Rubertsson, C., Borjesson, K., Berglund, A., Josefsson, A., and Sydsjo, G. (2011). The Swedish validation of Edinburgh Postnatal Depression Scale (EPDS) during pregnancy. Nord. J. Psychiatry 65, 414-418. doi: 10.3109/08039488.2011. 590606

Schofield, A. V., and Bernard, O. (2013). Rho-associated coiled-coil kinase (ROCK) signaling and disease. Crit. Rev. Biochem. Mol. Biol. 48, 301-316. doi: 10.3109/10409238.2013.786671

Shi, J., and Wei, L. (2013). Rho kinases in cardiovascular physiology and pathophysiology: the effect of fasudil. J. Cardiovasc. Pharmacol. 62, 341-354. doi: 10.1097/FJC.0b013e3182a3718f
Smyth, G. K. (2004). Linear models and empirical Bayes methods for assessing differential expression in microarray experiments. Stat. Appl. Genet. Mol. Biol. 3:Article 3. doi: 10.2202/1544-6115.1027

Smyth, G. K. (2005). "Limma:linear models for microarray data," in Bioinformatics and Computational Biology Solutions using $R$ and Bioconductor, eds R. Gentlemen, V. Carey, S. Dudoit, R. Irizarry, and W. Huber (NewYork, NY: Springer), 397-420.

Sturn, A., Quackenbush, J., and Trajanoski, Z. (2002). Genesis: cluster analysis of microarray data. Bioinformatics 18, 207-208. doi: 10.1093/bioinformatics/18.1.207

Tran, H., Pankov, R., Tran, S. D., Hampton, B., Burgess, W. H., and Yamada, K. M. (2002). Integrin clustering induces kinectin accumulation. J. Cell Sci. 115, 2031-2040.

Van Batenburg-Eddes, T., Brion, M. J., Henrichs, J., Jaddoe, V. W., Hofman, A., Verhulst, F. C., et al. (2012). Parental depressive and anxiety symptoms during pregnancy and attention problems in children: a cross-cohort consistency study. J. Child Psychol. Psychiatry 54, 591-600. doi: 10.1111/jcpp.12023

Wakabayashi, J., Zhang, Z., Wakabayashi, N., Tamura, Y., Fukaya, M., Kensler, T. W., et al. (2009). The dynamin-related GTPase Drp1 is required for embryonic and brain development in mice. J. Cell Biol. 186, 805-816. doi: $10.1083 /$ jcb. 200903065

Wan, B., Wang, X. R., Zhou, Y. B., Zhang, X., Huo, K., and Han, Z. G. (2010). C12ORF39, a novel secreted protein with a typical amidation processing signal. Biosci. Rep. 30, 1-10. doi: 10.1042/BSR20080156

Waters, C. S., Hay, D. F., Simmonds, J. R., and van Goozen, S. H. (2014). Antenatal depression and children's developmental outcomes: potential mechanisms and treatment options. Eur. Child Adolesc. Psychiatry 23, 957-971. doi: 10.1007/s00787-014-0582-3

Wei, L., Roberts, W., Wang, L., Yamada, M., Zhang, S., Zhao, Z., et al. (2001). Rho kinases play an obligatory role in vertebrate embryonic organogenesis. Development 128, 2953-2962.

Zeck, W., Widberg, C., Maylin, E., Desoye, G., Lang, U., McIntyre, D., et al. (2008). Regulation of placental growth hormone secretion in a human trophoblast model-the effects of hormones and adipokines. Pediatr. Res. 63, 353-357. doi: 10.1203/01.pdr.0000304935.19183.07

Conflict of Interest Statement: The authors declare that the research was conducted in the absence of any commercial or financial relationships that could be construed as a potential conflict of interest.

Received: 30 October 2014; accepted: 20 December 2014; published online: 13 January 2015.

Citation: Olivier JDA, Åkerud H, Skalkidou A, Kaihola H and Sundström-Poromaa I (2015) The effects of antenatal depression and antidepressant treatment on placental gene expression. Front. Cell. Neurosci. 8:465. doi: 10.3389/fncel.2014.00465 This article was submitted to the journal Frontiers in Cellular Neuroscience. Copyright () 2015 Olivier, Akerud, Skalkidou, Kaihola and Sundström-Poromaa. This is an open-access article distributed under the terms of the Creative Commons Attribution License (CC BY). The use, distribution or reproduction in other forums is permitted, provided the original author $(s)$ or licensor are credited and that the original publication in this journal is cited, in accordance with accepted academic practice. No use, distribution or reproduction is permitted which does not comply with these terms. 